\title{
Qualidade microbiológica e vida útil de filés defumados de tilápia-do-nilo sob refrigeração ou congelamento
}

\author{
Maria Luiza Rodrigues de Souza Franco(1), Luiz Augusto do Amaral(2), Elisabete Maria Macedo Viegas ${ }^{(3)}$, \\ Sérgio do Nascimento Kronka ${ }^{(4)}$, Eliane Gasparino( ${ }^{(1)}$, Jane Martha Graton Mikcha ${ }^{(5)}$ e Ana Paula Del Vesco ${ }^{(1)}$ \\ (1)Universidade Estadual de Maringá (UEM), Departamento de Zootecnia, Avenida Colombo, no 5.790, Jardim Universitário, \\ CEP 87020-900 Maringá, PR. E-mail: mlrsouza@uem.br, egasparino@uem.br, apaulavesco@gmail.com (2)Universidade Estadual \\ Paulista (Unesp), Centro de Aquicultura, Via de Acesso Prof. Paulo D. Castellane, s/no, CEP $14884-900$ Jaboticabal, SP. \\ E-mail: lamaral@fcav.unesp.br (3)Universidade de São Paulo, Faculdade de Zootecnia e Engenharia de Alimentos, Avenida Duque \\ de Caxias Norte, № 225, CEP 13635-900, Pirassununga, SP. E-mail: emviegas@usp.br (4)Unesp, Departamento de Ciências Exatas. \\ E-mail: skronka@yahoo.com.br ${ }^{(5)}$ UEM, Departamento de Análises Clínicas e Biomedicina. E-mail: jmgmikcha@uem.br
}

Resumo - O objetivo deste trabalho foi avaliar a qualidade microbiológica e a vida útil de filés de tilápia-do-nilo, submetidos a diferentes métodos de defumação e condições de armazenamento. Foram utilizados dois processos de defumação (a frio ou a quente), em filés com ou sem pigmentação. Os produtos foram armazenados sob refrigeração ou congelados, e monitorados por 28 dias para avaliação da vida útil. Os filés congelados foram monitorados continuamente por 146 dias, apenas para a análise de ácido tiobarbitúrico (TBA). Defumação a quente e a frio reduziram a quantidade de coliformes, respectivamente em $99,78 \%$ e $97,80 \%$. O armazenamento do produto sob refrigeração permitiu a redução de $99,73 \%$ dos coliformes, e o armazenamento sob congelamento os reduziu em $99,83 \%$. Os valores encontrados de coliformes fecais estiveram dentro do limite permitido. Os valores de TBA nos filés atingiram o máximo no $14^{\circ}$ dia de armazenamento. Os valores de TBA nos tratamentos sob refrigeração foram superiores aos daqueles sob congelamento e, também, em filés defumados a frio, em comparação aos defumados a quente. O processo de defumação a quente, com posterior armazenamento sob congelamento, é a técnica mais apropriada para assegurar qualidade e maior período de vida útil para os filés de tilápia-do-nilo, independentemente do processo de pigmentação.

Termos para indexação: Oreochromis niloticus, Staphylococcus aureus, coliformes fecais, defumação a frio, defumação a quente.

\section{Microbiological quality and shelf life of smoked fillets of Nile tilapia under refrigeration or freezing}

\begin{abstract}
The objective of this work was to evaluate the microbiological quality and shelf life of Nile tilapia fillets subjected to different smoking methods and storing conditions. Two smoking processes (cold or hot) were used in fillets with or without pigmentation. Products were stored under refrigeration or freezing, and monitored continually for 28 days for evaluation of their shelf life. Frozen fillets were monitored for 146 days for analysis of thiobarbituric acid (TBA) only. Hot- and cold-smoking reduced the coliform quantity, respectively, by $99.78 \%$ and $97.80 \%$. Product storage under refrigeration allowed a $99.73 \%$ coliform reduction, and storage under freezing reduced them by $99.83 \%$. Fecal coliform values were within the allowed limits. TBA values in fillets reached their maximum on the $14^{\text {th }}$ storage day. TBA values were higher in treatments under refrigeration storage than in those under freezing, as well as in cold-smoked fillets in comparison to the hot-smoked ones. Hot-smoked process, followed by refrigeration storage, is the most adequate technique to ensure quality and a larger shelf life for Nile tilapia fillets, regardless of pigmentation process.
\end{abstract}

Index terms: Oreochromis niloticus, Staphylococcus aureus, fecal coliforms, cold smoking, hot smoking.

\section{Introdução}

A tilápia (Oreochromis niloticus) é uma das espécies de peixe mais cultivadas mundialmente e, também, tem mostrado a sua grande versatilidade, com bons resultados quando criada em água salgada (Iqbal et al., 2012). Destaca-se por apresentar crescimento rápido e rusticidade, entre outras qualidades (Meurer et al., 2003). Apropriada para a indústria de filetagem, a tilápia tem ampla aceitação pelo mercado consumidor, pela inexistência de espinhas em forma de $\mathrm{Y}$ em seu filé, por isso, é uma espécie de grande interesse para a piscicultura (Boscolo \& Feinden, 2007). 
As perspectivas atuais indicam aumento do consumo de produtos industrializados, já que, a cada dia, a sociedade destina menos tempo ao preparo de suas refeições (Ferreira et al., 2002). Esses produtos geralmente são comercializados congelados, porém esta técnica não é totalmente eficiente quanto à segurança microbiológica e, além disso, tem custo elevado (Souza et al., 2007). Quando mantidos em refrigeração, os produtos cárneos têm a vida útil reduzida, em comparação à de produtos congelados. $O$ processo de defumação, seguido de refrigeração desse produto, é uma alternativa para eliminar os patógenos dos produtos alimentícios.

A defumação de peixes é empregada com finalidades preservativas, em virtude dos efeitos combinados da salga, cocção, secagem e deposição de substâncias químicas bactericidas presentes na fumaça, como fenóis, aldeídos e ácidos orgânicos (Assis et al., 2009). Além destes benefícios, a defumação confere ao filé in natura qualidades sensoriais, como aroma, sabor, coloração e, também, agrega valor ao produto (Cardinal et al., 2006).

Peixes defumados são produtos que apresentam grande facilidade no preparo e utilização e podem ser encontrados nos mercados em diversas formas. Peixes de porte pequeno, normalmente, são defumados inteiros, e os maiores, em filés, pedaços ou partes, com cortes com ou sem pele (Souza et al., 2004, 2005).

O tempo de vida útil é um dos atributos mais importantes de todos os alimentos e pode ser definido como o tempo que se passa desde a produção e embalagem até o ponto em que o alimento se torna inaceitável para o consumo (Forsythe, 2002). Para determinar a vida útil de produtos cárneos, é comum que se estudem seus parâmetros microbiológicos, químicos e sensoriais (Mathias et al., 2010).

O objetivo deste trabalho foi avaliar a qualidade microbiológica e a vida útil de filés de tilápia-do-nilo, submetidos a diferentes métodos de defumação (a frio e a quente) e condições de armazenamento (refrigeração e congelamento).

\section{Material e Métodos}

O experimento foi conduzido no Laboratório de Aquicultura, do Centro de Aquicultura (Caunesp) da Universidade Estadual Paulista.

Foram utilizadas 250 tilápias-do-nilo, que foram submetidas à depuração por 48 horas, em tanques de alvenaria com água corrente, e sem alimentação. Após este período os peixes foram abatidos, tendo sido antes submetidos à insensibilização por choque térmico (gelo e água, 1:1). Os peixes foram lavados, descabeçados, eviscerados, e a pele e os filés foram removidos. Os 500 filés obtidos das 250 tilápias foram identificados (placa metálica), embalados a vácuo e mantidos resfriados em caixas com gelo, por 12 horas, para realização das análises microbiológicas, atividade de água e umidade (in natura, testemunha).

Os filés foram submetidos à defumação no Abatedouro-Escola, da Universidade de São Paulo, em Pirassununga, SP. Os filés foram defumados em defumador industrial da marca Arprotec, com geração de fumaça por fricção da madeira. Para tanto, a metade da quantidade dos filés foi imersa em solução de salmoura a $20 \%$, à proporção de $2: 1$ (volume da salmoura/peso), por $30 \mathrm{~min}$ e, em seguida, os filés foram lavados em água corrente, para eliminar o excesso de sal de sua superfície. Deste lote, três filés identificados foram separados para a determinação de cloreto de sódio. A outra metade dos filés identificados foi submetida ao mesmo processo de salga e foi lavada e pigmentada por imersão em solução de água (1:1), com extrato de urucum $\left(6 \mathrm{~mL} \mathrm{~L}^{-1}\right)$, por $15 \mathrm{~min}$.

Decorrido esse período, os filés foram retirados da solução e colocados nas telas dos carrinhos de defumação e levados para a câmara fria $\left(0-1^{\circ} \mathrm{C}\right)$, onde permaneceram por sete horas (para perder água superficial). Os filés que não sofreram o processamento de pigmentação também passaram pela câmara fria. Após isto, foram colocados na câmara de defumação, para secagem parcial (defumação a frio a $30^{\circ} \mathrm{C}$, e a quente a $50^{\circ} \mathrm{C}$ ), por $60 \mathrm{~min}$. Em seguida, foi adicionada fumaça ao processo, e a temperatura na defumação a quente variou de $50^{\circ} \mathrm{C}$ a $80^{\circ} \mathrm{C}$ (após a adição da fumaça), por três horas. Adefumação a frio foi realizada entre $30^{\circ} \mathrm{C}$ e $40^{\circ} \mathrm{C}$ e prolongou-se por cinco horas. Ao término da defumação, os filés foram submetidos a resfriamento em câmara fria $\left(0\right.$ a $\left.1^{\circ} \mathrm{C}\right)$, as placas metálicas foram retiradas, e os filés foram pesados, embalados a vácuo e identificados individualmente, de acordo com o método de defumação.

Logo após a defumação, separam-se aleatoriamente três filés por tratamento, que foram congelados a $-18^{\circ} \mathrm{C}$, para determinação da concentração de cloreto (Cuniff, 1995) no produto final.

A atividade de água (Aw) dos filés in natura e defumados foi determinada por medida direta em 
aparelho Aqualab Cx-2 (Decagon Devices Inc.) As amostras foram trituradas, colocadas no porta-amostras e previamente condicionadas a $25^{\circ} \mathrm{C}$ por $30 \mathrm{~min}$. $\mathrm{O}$ aparelho foi previamente calibrado com $\mathrm{NaCl} 6$ molar $(\mathrm{Aw}=0,76)$ a $25^{\circ} \mathrm{C}$. Foram utilizados, para análise da Aw, três filés in natura (testemunha) e 10 filés defumados, por tratamento.

Para avaliar o efeito do processo de defumação e pigmentação, quanto à atividade de água (Aw) e umidade, utilizou-se delineamento experimental inteiramente casualizado, em arranjo fatorial $2 \times 2$, mais uma testemunha (T0, filés in natura), com duas técnicas de defumação (T1, a quente; T2, a frio) e pigmentação com extrato de urucum (FCP, com extrato; FSP, sem extrato). Para o cloreto de sódio, utilizou-se o mesmo delineamento, porém, sem a testemunha.

Para a determinação do teor de umidade (Cuniff, 1995), utilizaram-se cinco filés de cada tratamento e in natura, que foram embalados e congelados a $-18^{\circ} \mathrm{C}$, para realização da análise.

Para a avaliação da vida útil, os filés referentes a cada tratamento (com ou sem pigmentação, submetidos à defumação a quente e a frio) foram distribuídos em bandejas de plástico e colocados em geladeira ou freezer. A temperatura média de armazenamento sob refrigeração foi de $6^{\circ} \mathrm{C}$, por 28 dias, e congelamento de $-18^{\circ} \mathrm{C}$, por 146 dias.

Para a avaliação da vida útil do filé defumado, quanto à microbiologia e à rancidez oxidativa (TBA), utilizou-se delineamento inteiramente casualizado, em arranjo fatorial $4 \times 2 \times 4$, com: cinco testemunhas (T0, filés in natura; T1, frio com pigmentação; T2, frio sem pigmentação; T3, quente com pigmentação; e T4, quente sem pigmentação); quatro métodos de defumação (M1, filé defumado a frio, com pigmentação; M2, filé defumado a frio, sem pigmentação; M3, filé defumado a quente, com pigmentação; e M4, filé defumado a quente, sem pigmentação); duas condições de armazenamento ( $\mathrm{C}$ 1, resfriamento; e $\mathrm{C} 2$, congelamento); e quatro períodos de armazenamento (P1, 7 dias; P2, 14 dias; P3, 21 dias; e P4, 28 dias após a defumação). Esse mesmo delineamento foi utilizado apenas para os filés submetidos ao congelamento até os 146 dias de estocagem.

Para verificar as condições de higiene e manipulação do pescado, os filés foram caracterizados microbiologicamente e, para avaliação do efeito da defumação sobre as características microbiológicas e ação da rancidez oxidativa, foram utilizados filés dos diferentes tratamentos, comparados à testemunha (filés não defumados - in natura, $\mathrm{n}=5$ ).

Para acompanhamento da vida útil, foram realizadas análises microbiológicas e teste de rancidez oxidativa, por meio da análise de: ácido tiobarbitúrico TBA (mg kg-1 de malonaldeído) (Vyncke, 1970), semanalmente, por 28 dias, para os filés armazenados sob refrigeração e congelamento. Para análises microbiológicas, foram utilizados cinco filés com e sem pigmentação, por método de defumação, e três filés para análise de TBA, em razão do armazenamento (geladeira e freezer). Após esse período de 28 dias, foram realizadas análises de TBA, com período variável de 7 a 30 dias entre as análises, em razão da redução dos valores de TBA, para acompanhamento da oxidação de lipídios dos filés congelados, por mais quatro meses, tendo-se utilizado três filés por tratamento.

As análises microbiológicas foram realizadas em cinco filés por tratamento. A contagem de coliformes fecais foi feita pela técnica da membrana filtrante, e a contagem de Staphylococcus coagulase positiva e o isolamento de Salmonella sp. foram feitos conforme Vanderzant \& Splittstoesser (1992).

Para avaliação sensorial, após 28 dias de armazenamento, foram preparadas amostras padronizadas em massa ( $25 \mathrm{~g}$ ) e posição do corte no filé de cada método de defumação e cada forma de armazenamento, ou seja, geladeira e freezer. Os provadores $(n=30)$ não treinados receberam de maneira aleatória as amostras e avaliaram a presença ou não do odor de ranço, por meio de uma ficha para análise sensorial, para anotar o número das amostras em que constava odor de ranço.

Os resultados das leituras de Staphylococcus sp. e coliformes fecais foram transformados para logaritmo $[\ln (\mathrm{x}+0,5)]$ e expressos em $\ln \mathrm{UFC}^{-1}$. Todos os resultados das análises microbiológicas, determinação de TBA, cloreto de sódio e umidade dos filés foram submetidos à análise de variância, e as médias foram comparadas pelo teste de Tukey, a $5 \%$ de probabilidade, conforme o programa SAS.

\section{Resultados e Discussão}

Com o processo de defumação, houve redução significativa dos coliformes fecais e de Staphylococcus sp., independentemente da técnica de defumação utilizada. Os filés in natura apresentaram 
Salmonella sp., no entanto, com a defumação, esse microrganismo foi eliminado (Tabela 1). Como foi negativa a análise de Staphylococcus coagulase positiva, foram apresentados e discutidos apenas os resultados obtidos para Staphylococcus, independentemente da espécie. As análises de Salmonella sp. foram repetidas por duas semanas, entretanto, decidiu-se não realizar mais análises, no decorrer do período de armazenamento dos filés em geladeira e freezer, já que não foi mais detectada presença de Salmonella sp. nos filés defumados.

Os valores de coliformes fecais, observados nos filés defumados a frio, estavam próximos aos valores considerados como padrão microbiológico (Agência Nacional de Vigilância Sanitária, 2001) e inferiores ao limite permitido, quando a defumação foi realizada a quente. Portanto, logo após a defumação, com exceção da defumação a frio com pigmentação, todos os filés defumados estavam de acordo com os padrões microbiológicos para consumo (Tabela 2). Assim, pode-se dizer que os processos de defumação, em especial aquele realizado a quente, foram eficientes na remoção desses microrganismos, fato importante quanto ao risco que alimentos contaminados podem representar à saúde dos consumidores. Ressalta-se, ainda, sob o aspecto de saúde pública, que alguns microrganismos, como os do gênero Staphylococcus, também constituem risco à população, pois, algumas cepas podem produzir toxinas termoestáveis e provocar intoxicação alimentar, desencadeando severos processos de gastroenterite (Marchi et al., 2012).

A temperatura da defumação é muito importante na redução desses microrganismos, juntamente com a ação dos bactericidas presentes na fumaça (Bressan, 2002). A duração do fluxo de fumaça aplicada ao processo também influenciou a eliminação de microrganismos, pois, pode-se constatar que, apesar de baixa, a temperatura $\left(40^{\circ} \mathrm{C}\right)$ aplicada à defumação a frio foi suficiente para eliminar Salmonella sp. presente nos filés in natura (Tabela 1).

A técnica de defumação influenciou a perda de água dos filés (Tabela 3). A defumação a quente reduziu a umidade em $14,80 \%$, enquanto, a frio, a perda foi de $10,68 \%$. Essa maior perda se atribui à elevada temperatura, aplicada à técnica a quente (50 a $80^{\circ} \mathrm{C}$ ) por três horas. Constatou-se, também, que houve correlação positiva dos coliformes fecais e Staphylococcus sp. com a atividade de água $\left(\mathrm{r}=0,97^{* *}\right.$ e $\mathrm{r}=0,93^{*}$, respectivamente) e umidade $\left(\mathrm{r}=0,99^{* *}\right.$ e $\mathrm{r}=0,97^{* *}$, respectivamente) dos filés defumados.

A atividade de água (Aw) pode ser um índice seguro, para se avaliar o potencial de estabilidade biológica de produtos curados, especialmente quanto à deterioração do alimento por microrganismos. Os microrganismos apresentam diferentes graus de tolerância à atividade da água, mas, em geral, o limite mínimo da Aw para o crescimento da maioria das bactérias é de 0,90. Staphylococcus aureus são exceções a essa regra, pois, em condição aeróbia, essa espécie pode crescer a 0,86 (Editora Insumos, 2010).

Gonçalves \& Cezarini (2008) relatam teor de umidade de $57,35 \%$ em filé de jundiá (Rhamdia quelen), defumado tradicionalmente entre 71 e $82^{\circ} \mathrm{C}$, e adição de fumaça por três horas e 15 min. Também, Souza et al. (2004) citam valores de umidade de $63 \%$ em filé de tilápia-do-nilo, submetido à defumação tradicional entre 50 e $90^{\circ} \mathrm{C}$, por quatro horas de adição de fumaça. $\mathrm{O}$ teor de umidade do pescado defumado é importante para a avaliação de sua qualidade organoléptica, apesar da perda parcial da água ser importante para os efeitos conservantes da defumação, pois, à medida que diminui a umidade, o produto fica, cada vez mais, com consistência seca e dura, o que faz diminuir sua aceitabilidade (Gonçalves \& Prentice-Hernández, 1998).

A pigmentação aplicada aos filés não influenciou o processo de perda de água destes durante a defumação. Entretanto, os filés pigmentados apresentaram menor

Tabela 1. Contagem (UFC g ${ }^{-1}$ ) de coliformes fecais, Staphylococcus sp. e Salmonella sp., analisados nos filés in natura e logo após a execução dos métodos defumação, a quente e a frio, independentemente da pigmentação.

\begin{tabular}{|c|c|c|c|c|c|c|c|}
\hline \multirow[t]{3}{*}{ Microrganismos } & \multicolumn{5}{|c|}{ Técnica de defumação } & \multicolumn{2}{|c|}{ Legislação $^{(1)}$} \\
\hline & \multirow{2}{*}{ 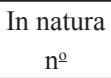 } & \multicolumn{2}{|c|}{ Frio (T1) } & \multicolumn{2}{|c|}{ Quente (T2) } & \multirow[t]{2}{*}{ In natura } & \multirow[t]{2}{*}{ Defumado } \\
\hline & & $\mathrm{n}^{\mathrm{o}}$ & Redução (\%) & $\mathrm{n}^{\mathrm{o}}$ & Redução (\%) & & \\
\hline Coliformes fecais & $5,9 \times 10^{3}$ & $1,3 \times 10^{2}$ & $97,80 * *$ & $1,3 \times 10^{1}$ & $99,78 * *$ & $<10^{2}$ & $<10^{2}$ \\
\hline Staphylococcus sp. & $9,4 \times 10^{4}$ & $6,6 \times 10^{3}$ & $92,98 * *$ & $7,4 \times 10$ & $99,92 * *$ & - & - \\
\hline Salmonella sp. & Presente & Ausente & - & Ausente & - & Ausente & Ausente \\
\hline
\end{tabular}

(1)Legislação Agência Nacional de Vigilância Sanitária (2001). **Significativo a 1\% de probabilidade. 
valor numérico de perda de água, o que indica que o extrato de urucum, ao envolver o filé pode ser suficiente para proporcionar um bloqueio à perda de água (Tabela 3).

A técnica de defumação não influenciou o teor de sal dos filés defumados (Tabela 3). Mas, pode-se observar que os filés pigmentados apresentaram menor teor de cloreto de sódio do que os filés não pigmentados. Isso se deve à metodologia aplicada ao processo, pois, para a pigmentação, os filés foram imersos em uma solução de água com extrato de urucum $\left(6 \mathrm{~mL} \mathrm{~L}^{-1}\right)$, durante $15 \mathrm{~min}$, o que pode ter diminuído o teor do sal do tecido muscular, aplicado na etapa anterior, na salmouragem. Mesmo que os componentes da fumaça exerçam um efeito inibitório sobre os microrganismos, no produto defumado, poderá ocorrer a multiplicação destes durante o processo de defumação ou durante a estocagem à temperatura ambiente, se a concentração de $\mathrm{NaCl}$ for reduzida (Coppola et al., 1997). O teor de cloreto de sódio, na fração aquosa do produto, deve ser de $3 \%$, para que seja inibido o crescimento de qualquer

Tabela 2. Médias dos dados reais e transformadas $[\ln (\mathrm{x}+0,5)]$ dos números de coliformes fecais $\mathrm{e}$ Staphylococcus sp. dos filés resfriados e congelados de tilápia-do-nilo, defumados pelo período de vida útil de 28 $\operatorname{dias}^{(1)}$

\begin{tabular}{|c|c|c|c|c|}
\hline \multirow[t]{2}{*}{ Fatores } & \multicolumn{2}{|c|}{ Coliformes fecais } & \multicolumn{2}{|c|}{ Staphylococcus $\mathrm{sp}$} \\
\hline & $\begin{array}{l}\text { Transformados }^{(1)} \\
\left(\ln \mathrm{UFC} \mathrm{g}^{-1}\right)\end{array}$ & $\begin{array}{c}\text { Reais } \\
\left(\mathrm{UFC} \mathrm{g}^{-1}\right)\end{array}$ & $\begin{array}{c}\text { Transformados } \\
\left(\mathrm{UFC} \mathrm{g}^{-1}\right)\end{array}$ & $\begin{array}{c}\text { Reais } \\
\left(\mathrm{UFC} \mathrm{g}^{-1}\right)\end{array}$ \\
\hline Frio com pigmentação & $2,76 a$ & $1,58 \times 10$ & $9,84 \mathrm{a}$ & $1,88 \times 10^{4}$ \\
\hline Frio sem pigmentação & $2,78 \mathrm{a}$ & $1,61 \times 10$ & $10,40 \mathrm{a}$ & $3,39 \times 10^{4}$ \\
\hline Quente com pigmentação & $2,30 \mathrm{a}$ & $1,00 \times 10$ & $11,01 \mathrm{a}$ & $6,05 \times 10^{4}$ \\
\hline Quente sem pigmentação & $2,44 \mathrm{a}$ & $1,15 \times 10$ & $9,70 \mathrm{a}$ & $1,63 \times 10^{4}$ \\
\hline Geladeira & $2,77 \mathrm{a}$ & $1,59 \times 10$ & $11,48 \mathrm{a}$ & $9,68 \times 10^{4}$ \\
\hline Freezer & $2,36 \mathrm{~b}$ & $1,06 \times 10$ & $9,01 \mathrm{~b}$ & $8,18 \times 10^{3}$ \\
\hline 7 dias & $3,02 \mathrm{a}$ & $2,05 \times 10$ & $11,06 \mathrm{a}$ & $6,36 \times 10^{4}$ \\
\hline 14 dias & $2,63 \mathrm{ab}$ & $1,39 \times 10$ & $10,38 b$ & $3,22 \times 10^{4}$ \\
\hline 21dias & $2,30 \mathrm{~b}$ & $1,00 \times 10$ & $9,45 b$ & $1,27 \times 10^{4}$ \\
\hline 28 dias & $2,33 b$ & $1,03 \times 10$ & $10,09 \mathrm{~b}$ & $2,41 \times 10^{4}$ \\
\hline \multicolumn{5}{|l|}{ Testemunhas } \\
\hline Filés, antes de defumar & $8,68 \mathrm{a}$ & $5,88 \times 10^{3}$ & $11,45 \mathrm{a}$ & $9,39 \times 10^{4}$ \\
\hline Frio, com pigmentação & $5,28 \mathrm{~b}$ & $1,96 \times 10^{2}$ & $9,88 \mathrm{~b}$ & $1,95 \times 10^{4}$ \\
\hline Frio, sem pigmentação & $4,52 \mathrm{bc}$ & $9,18 \times 10$ & $7,71 \mathrm{bc}$ & $2,23 \times 10^{3}$ \\
\hline Quente, com pigmentação & $2,30 \mathrm{~d}$ & $1,00 \times 10$ & $5,22 \mathrm{~cd}$ & $1,85 \times 10^{2}$ \\
\hline Quente, sem pigmentação & $2,90 \mathrm{~cd}$ & $1,82 \times 10$ & $3,39 \mathrm{~d}$ & $2,97 \times 10$ \\
\hline Entre testemunhas & $30,01 * *$ & - & $13,24 * *$ & - \\
\hline Fatorial $\mathrm{x}$ testemunhas & $96,73^{* *}$ & - & $38,84^{* *}$ & - \\
\hline$\overline{\mathrm{CV}(\%)}$ & 35,81 & - & 20,49 & - \\
\hline
\end{tabular}

microrganismo, em particular o Clostridium botulinum (Gonçalves \& Prentice-Hernández, 1998).

Os diferentes métodos de defumação não tiveram efeito sobre a contagem de coliformes fecais, considerando-se os 28 dias de armazenamento. Com o armazenamento, houve redução dos microrganismos analisados, influenciada pelo tempo de estocagem, percebida a partir do $14^{\circ}$ dia, tanto de coliformes fecais como de Staphylococcus sp. (Tabela 2). No freezer, essa redução foi significativamente maior do que em geladeira. Assim, pode-se verificar que o número de microrganismos presentes nos filés pode ser diminuído ou estabilizado com a temperatura de armazenamento.

Para Staphylococcus sp., houve interação significativa entre os fatores, quanto ao método de defumação e condição de armazenamento $(\mathrm{M} \times \mathrm{C})$ (Figura 1), bem como quanto à condição de armazenamento e período de estocagem $(\mathrm{C} \times \mathrm{P})$ (Figura 1). Na contagem de Staphylococcus sp., pode-se observar que, na geladeira, o M3 (filés defumados a quente, com pigmentação) foi o que apresentou maior quantidade de Staphylococcus sp. (Figura 1).

Filés armazenados no freezer, independentemente do método de defumação, apresentaram menor quantidade de Staphylococcus sp. (Figura 1); este resultado permite inferir que a temperatura de estocagem utilizada $\left(-18^{\circ} \mathrm{C}\right)$ proporcionou a redução, em especial desse microrganismo. Jesus et al. (2001) também observaram redução da atividade microbiana, quando a carne de peixes foi estocada congelada.

A rancidez ou oxidação de lipídios é a deterioração mais importante que ocorre em produtos cárneos.

Tabela 3. Valores médios de atividade de água, umidade e teor de cloreto, nos filés de tilápia-do-nilo defumados pela técnica a frio ou a quente, com ou sem pigmentação, antes do armazenamento, comparados com filés in natura ${ }^{(1)}$.

\begin{tabular}{lccc}
\hline Fatores & $\begin{array}{c}\text { Atividade } \\
\text { de água }\end{array}$ & $\begin{array}{c}\text { Umidade } \\
(\%)\end{array}$ & $\begin{array}{c}\text { Cloreto de } \\
\text { sódio }(\%)\end{array}$ \\
\hline Defumação a frio & $0,97 \mathrm{a}$ & $72,24 \mathrm{a}$ & $2,90 \mathrm{a}$ \\
Defumação a quente & $0,95 \mathrm{~b}$ & $68,90 \mathrm{~b}$ & $2,77 \mathrm{a}$ \\
Com pigmentação & $0,97 \mathrm{a}$ & $71,45 \mathrm{a}$ & $2,55 \mathrm{~b}$ \\
Sem pigmentação & $0,95 \mathrm{~b}$ & $69,67 \mathrm{a}$ & $3,12 \mathrm{a}$ \\
Testemunha (filés in natura) & 1,02 & 80,83 & - \\
Testemunha x fatorial & $47,97 * *$ & $102,62 * *$ & - \\
\hline CV (\%) & \multicolumn{1}{c}{1,60} & 2,80 & 14,65 \\
\hline \multirow{2}{*}{ (1) Médias seguidas de letras iguais, nas colunas, não diferem pelo teste de } \\
Tukey, a 5\% de probabilidade. **Significativo a 1\% de probabilidade.
\end{tabular}

Pesq. agropec. bras., Brasília, v.48, n.8, p.1071-1079, ago. 2013 DOI: 10.1590/S0100-204X2013000800037 
O índice de TBA (ácido 2-tiobarbitúrico) é utilizado no controle de qualidade desses produtos, pois fornece informações valiosas a respeito do estado oxidativo e da predição de rancidez do alimento analisado (Osawa et al., 2005). Entretanto, a qualidade do produto final está relacionada à qualidade da matéria prima utilizada no processamento (Komiyama et al., 2007).

Logo após a defumação dos filés de tilápia-do-nilo, o valor de TBA para os filés defumados a frio foi superior ao dos defumados a quente (Figura 2). Os filés defumados com pigmentação apresentaram valores de TBA significativamente inferiores aos não pigmentados. Valores de TBA, entre outros fatores, estão relacionados ao tipo de produto analisado.

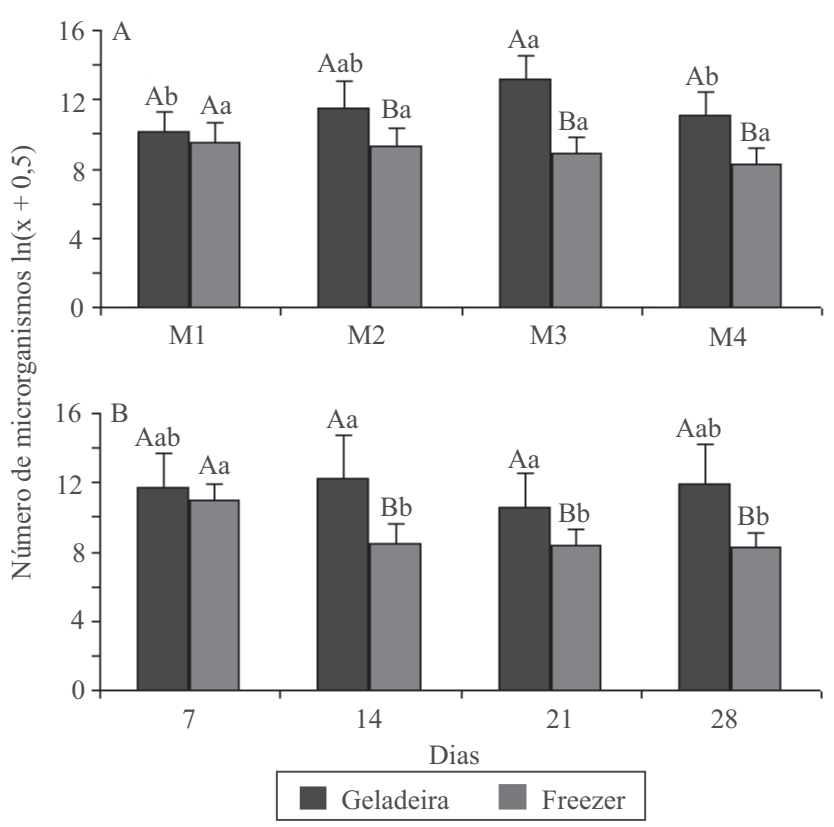

Figura 1. Médias transformadas $[\ln (\mathrm{x}+0,5)]$ dos valores observados de Staphylococcus sp. - do desdobramento da interação dos métodos de defumação e condição de armazenamento (A) e do desdobramento da interação da condição de armazenamento e períodos de estocagem (B) - nos filés com e sem pigmentação, defumados a frio e a quente. Médias seguidas de letras maiúsculas iguais, dentro de cada método ou período de estocagem, e letras minúsculas iguais, dentro de cada sistema de armazenamento (geladeira ou freezer), não diferem pelo teste de Tukey, a 5\% de probabilidade. M1, defumação a frio, com pigmentação; M2, frio, sem pigmentação; M3, quente, com pigmentação; M4, quente, com defumação.
Pescados, em geral, apresentam maiores valores de TBA do que as demais carnes, em razão de sua rica composição de ácidos graxos poli-insaturados de cadeia longa (Osawa et al., 2005).

Carotenoides como o urucum são substâncias inibidoras das reações de $\mathrm{O}_{2}$ (Torres \& Martins, 2001). Assim, o pigmento utilizado (extrato de urucum) pode ter contribuído para a redução da rancidez oxidativa. Como o urucum, os fenóis encontrados na fumaça também são antioxidantes naturais e também reagem ou interferem na participação do $\mathrm{O}_{2}$; ambas as substâncias apresentam o efeito de retardar a reação de oxidação. Assim, o baixo teor de sal e o pigmento adicionado ao processo de defumação, associados ao efeito antioxidante da fumaça, podem ter influenciado a redução do valor de TBA dos filés.

A vida útil de produtos defumados pode ser influenciada por diversos fatores, entre os quais estão: a metodologia aplicada para a defumação (a frio ou a quente); a concentração de sal; o tempo de exposição de fumaça; e a temperatura aplicada ao processo. Além destes fatores, também é importante observar as características relacionadas à apresentação do produto final (filé inteiro ou fatiado, peixe inteiro, tipo de embalagem etc.) e a temperatura de estocagem (Ferreira et al., 2002; Silva et al., 2010).

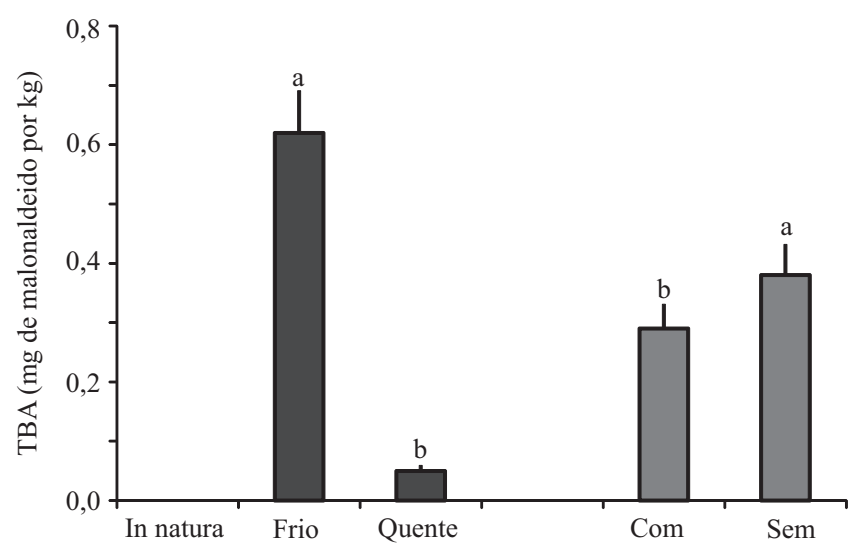

Figura 2. Valores médios de TBA dos filés in natura e imediatamente após a defumação. Quente, defumação a quente; frio, defumação a frio; com, defumação com o uso do processo de pigmentação; sem, defumação sem o uso do processo de pigmentação. Médias de um mesmo fator, seguidas de letras iguais, não diferem pelo teste de Tukey, a $5 \%$ de probabilidade. 
Não há, na legislação brasileira, um valor de TBA estabelecido como seguro para o consumo humano. Variação dos valores de TBA, durante o período de armazenamento de peixes defumados, também foi encontrada por Özogul et al. (2005).

Ao considerar os métodos de defumação, ao longo dos períodos de armazenamento em geladeira, por 28 dias, e freezer, por 146 dias, notou-se que os filés defumados a frio, com ou sem pigmentação, apresentaram maior valor de TBA do que os defumados a quente, independentemente de estarem em geladeira ou freezer (Tabela 4 e 5). Em geral, houve aumento dos valores de TBA, quanto ao tempo de armazenamento, a partir do $7^{\circ}$ dia, com ocorrência de um pico de TBA aos 14 dias (Tabela 5).

Quanto à percepção de odor desagradável ou de ranço pelos provadores, os resultados mostraram que os filés armazenados em geladeira apresentaram maior odor de ranço do que os armazenados em freezer. Entre os filés armazenados em geladeira, os tratados pelo método de defumação a frio, sem pigmentação (M2), foram os que mais apresentaram odor (percebido por $30 \%$ dos provadores), seguidos pelos filés dos métodos M1 (a frio, com pigmentação), M3 (a quente, sem pigmentação), e M4 (a quente, com pigmentação), o que corresponde a 13,33, 10 e $10 \%$ dos provadores, respectivamente. No freezer, o método M2 também foi o que se mostrou mais inadequado $(6,66 \%$ dos provadores detectaram odor desagradável). Nenhum dos provadores percebeu qualquer odor nos filés defumados a quente e sem pigmentação (M3) armazenados no freezer.

Com as informações dos valores de TBA, podese dizer que os filés defumados a frio e a quente e armazenados na geladeira e freezer podem ser consumidos durante todos os períodos avaliados no presente trabalho, já que resultados da literatura mostram que a carne de peixe com valores de TBA entre 0,7 e 1,4 apresenta qualidade aceitável para consumo humano, apesar de os produtos estarem ligeiramente rancificados (Osawa et al., 2005).

Tabela 4. Valores médios de ácido tiobarbitúrico (TBA), dos filés defumados a frio e a quente, com ou sem pigmentação, durante o período de estocagem de 28 dias e condição de armazenamento $^{(1)}$.

\begin{tabular}{lc}
\hline Fatores de variação & TBA $\left(\mathrm{mg} \mathrm{kg}^{-1}\right.$ de malonaldeído $)$ \\
\hline Frio, com pigmentação & $0,92 \mathrm{a}$ \\
Frio, sem pigmentação & $1,11 \mathrm{a}$ \\
Quente, com pigmentação & $0,46 \mathrm{~b}$ \\
Quente, sem pigmentação & $0,52 \mathrm{~b}$ \\
\hline Geladeira & $0,74 \mathrm{a}$ \\
Freezer & $0,75 \mathrm{a}$ \\
\hline 7 dias & $0,72 \mathrm{~b}$ \\
14 dias & $1,09 \mathrm{a}$ \\
21 dias & $0,45 \mathrm{c}$ \\
28 dias & $0,74 \mathrm{~b}$ \\
\hline CV $(\%)$ & 25,55 \\
\hline
\end{tabular}

(1)Médias seguidas de letras iguais, nas colunas, não diferem pelo teste de Tukey, a $5 \%$ de probabilidade.

Tabela 5. Valores médios do desdobramento da interação do método de defumação ${ }^{(1)}(\mathrm{M})$ e períodos de estocagem $(\mathrm{P})$, em geladeira (28 dias) e freezer (146 dias), quanto ao ácido tiobarbitúrico (TBA) em filés de tilápia-do-nilo ${ }^{(2)}$.

\begin{tabular}{|c|c|c|c|c|c|c|c|c|}
\hline \multirow{2}{*}{$\begin{array}{l}\text { Período } \\
\text { (dias) }\end{array}$} & \multicolumn{4}{|c|}{ Geladeira } & \multicolumn{4}{|c|}{ Freezer } \\
\hline & M1 & M2 & M3 & M4 & M1 & M2 & M3 & M4 \\
\hline $\mathrm{P} 0=0$ & $0,56 \mathrm{BCb}$ & $0,68 \mathrm{Ba}$ & $0,03 \mathrm{Bc}$ & $0,08 \mathrm{Bc}$ & $0,55 \mathrm{CDb}$ & $0,68 \mathrm{Bb}$ & $0,03 \mathrm{Cc}$ & $0,77 \mathrm{Ca}$ \\
\hline $\mathrm{P} 1=7$ & $0,93 \mathrm{ABa}$ & $0,99 \mathrm{ABa}$ & $0,44 \mathrm{Bb}$ & $0,39 \mathrm{ABb}$ & $0,75 \mathrm{BCb}$ & $1,28 \mathrm{Aa}$ & $0,48 \mathrm{ABb}$ & $0,53 \mathrm{ABb}$ \\
\hline $\mathrm{P} 2=14$ & $1,29 \mathrm{Aa}$ & $1,29 \mathrm{Aa}$ & 0,94Aab & $0,59 \mathrm{Ab}$ & $1,43 \mathrm{Aa}$ & $1,54 \mathrm{Aa}$ & $0,84 \mathrm{Ab}$ & $0,82 \mathrm{Ab}$ \\
\hline $\mathrm{P} 3=21$ & $0,51 \mathrm{Ca}$ & $0,93 \mathrm{Aa}$ & $0,03 \mathrm{Bb}$ & $0,58 \mathrm{Aa}$ & 0,61BCDa & $0,63 \mathrm{Ba}$ & $0,003 \mathrm{Cc}$ & $0,29 \mathrm{BCb}$ \\
\hline $\mathrm{P} 4=28$ & $0,85 \mathrm{BCab}$ & $0,99 \mathrm{ABa}$ & $0,41 \mathrm{Bc}$ & $0,57 \mathrm{Abc}$ & $0,96 \mathrm{Ba}$ & $1,25 \mathrm{Aa}$ & $0,48 \mathrm{ABb}$ & $0,40 \mathrm{BCb}$ \\
\hline $\mathrm{P} 5=35$ & - & - & - & - & $0,40 \mathrm{CDa}$ & $0,42 \mathrm{Ba}$ & $0,00 \mathrm{Cb}$ & $0,04 \mathrm{Cb}$ \\
\hline$P 6=47$ & - & - & - & - & 0,60BCDa & $0,54 \mathrm{Bab}$ & $0,26 \mathrm{BCb}$ & $0,29 \mathrm{BCb}$ \\
\hline $\mathrm{P} 8=68$ & - & - & - & - & $0,35 \mathrm{Da}$ & $0,38 \mathrm{Ba}$ & $0,16 \mathrm{BCa}$ & $0,23 \mathrm{BCa}$ \\
\hline$P 9=89$ & - & - & - & - & $0,33 \mathrm{Da}$ & $0,44 \mathrm{Ba}$ & $0,14 \mathrm{BCa}$ & $0,21 \mathrm{BCa}$ \\
\hline $\mathrm{P} 10=120$ & - & - & - & - & $0,46 \mathrm{CDab}$ & $0,73 \mathrm{Ba}$ & $0,21 \mathrm{BCb}$ & $0,19 \mathrm{BCb}$ \\
\hline $\mathrm{P} 11=146$ & - & - & - & - & $0,54 \mathrm{CDa}$ & $0,61 \mathrm{Ba}$ & $0,11 \mathrm{BCb}$ & $0,16 \mathrm{BCb}$ \\
\hline
\end{tabular}

${ }^{(1)}$ M1, defumação a frio, com pigmentação; M2, frio, sem pigmentação; M3, quente, com pigmentação; M4, quente, com defumação. (2)Médias seguidas de letras iguais, maiúsculas nas colunas e minúsculas nas linhas, para cada condição de armazenamento, não diferem pelo teste de Tukey, a $5 \%$ de probabilidade. 


\section{Conclusões}

1. O processo de defumação a frio ou a quente de filés de tilápia-do-nilo promove redução de coliformes fecais e Staphylococcus sp.

2. Filés defumados a frio e a quente, armazenados na geladeira por 28 dias e em freezer por 146 dias, apresentam qualidade adequada para consumo.

3. O processo de defumação a quente, com posterior armazenamento sob congelamento é a técnica mais apropriada para assegurar qualidade e maior período de vida útil para os filés de tilápia-do-nilo, independentemente do processo de pigmentação.

\section{Referências}

AGÊNCIA NACIONAL DE VIGILÂNCIA SANITÁRIA. Resolução RDC no 12, de 02 de janeiro de 2001. Aprova regulamento técnico sobre os padrões microbiológicos para alimentos. Diário Oficial [da] República Federativa do Brasil, 10 jan. 2001.

ASSIS, M.F.; FRANCO, M.L.R.S.; STÉFANI, M.V.; FRANCO, N.P.; GODOY, L.C.; OLIVEIRA, A.C.; VISENTAINER, J.V.; SILVA, A.F.; HOCH, A.L.V. Efeito do alecrim na defumação da carne de rã (Rana catesbeiana): características sensoriais, composição e rendimento. Ciência e Tecnologia de Alimentos, v.29, p.553-556, 2009. DOI: 10.1590/S0101-20612009000300016.

BOSCOLO, W.R.; FEINDEN, A. Industrialização de tilápias. Toledo: GFM, 2007. 172p.

BRESSAN, M.C. Processamento de pescado de água doce. In: FEIRA DA PEQUENA AGROINDÚSTRIA, 2., 2002, Serra Negra. Anais. São Paulo: CATI, 2002. p.59-85.

CARDINAL, C.; CORNET, J.; SÉROT, T.; BARON, R. Effects of the smoking process on odour characteristics of smoked herring (Clupea harengus) and relationships with phenolic compound content. Food Chemistry, v.96, p.137-146, 2006. DOI: 10.1016/j. foodchem.2005.02.040.

COPPOLA, R.; LORIZZO, M.; SAOTTA, R.; SORRENTINO, E.; GRAZIA, L. Characterization of micrococci and staphylococci from soppressata molisana, a Southern Italy fermented sausage. Food Microbiology, v.14, p.47-53, 1997. DOI: 10.1006/ fmic.1996.0062.

CUNIFF, P. (Ed.). Official methods of analysis of AOAC International. $16^{\text {th }}$ ed. Gaithersburg: AOAC International, 1995. $2 \mathrm{v}$.

EDITORA INSUMOS. Conservação de alimentos por aditivos químicos. 2010. Disponível em: <http://www.insumos.com.br/ aditivos_e_ingredientes/materias/125.pdf $>$. Acesso em: 25 nov. 2010 .

FERREIRA, M.W.; SILVA, V.C.; BRESSAN, M.C.; FARIA, P.B.; VIEIRA, J.O.; ODA, S.H.I. Pescados processados: maior vida-de-prateleira e maior valor agregado. Lavras: Universidade Federal de Lavras, 2002. 26p. (Boletim de extensão rural).
FORSYTHE, S.J. Microbiologia da segurança alimentar. Porto Alegre: Artmed, 2002. 424p.

GONÇALVES, A.A.; CEZARINI, R. Agregando valor ao pescado de água doce: defumação de filés de jundiá (Rhamdia quelen). Revista Brasileira de Engenharia de Pesca, v.3, p.63-79, 2008.

GONÇALVES, A.A; PRENTICE-HERNÁNDEZ, C. Defumação líquida de anchova (Pomatomus saltatrix): efeito do processamento nas propriedades químicas e microbiológicas. Ciência e Tecnologia de Alimentos, v.18, p.438-443, 1998. DOI: 10.1590/ S0101-20611998000400016.

IQBAL, K.J.; QURESHI, N.A.; ASHRAF, M.; REHMAN, M.H.U.; KHAN, N.; JAVID, A.; ABBAS, F.; HUSHTAQ, M.M.H.; RASOOL, F.; MAJEED, H. Effect of different salinity levels on growth and survival of Nile tilapia (Oreochromis niloticus). The Journal of Animal and Plant Sciences, v.22, p.919-922, 2012.

JESUS, R.S. de; LESSI, E.; TENUTA-FILHO, A. Estabilidade química e microbiológica de "minced fish" de peixes amazônicos durante o congelamento. Ciência e Tecnologia de Alimentos, v.21, p.144-148, 2001. DOI: 10.1590/S0101-20612001000200004.

KOMIYAMA, C.M.; MENDES, A.A.; TAKAHASHI, S.E.; MOREIRA, J.; BORBA, H.B.A.; LEONEL, F.R.; ROÇA, R. de O.; ALMEIDA, I.C.L.P.; BALOG NETO, A. Características qualitativas de produtos elaborados com carne de frango pálida e normal. Ciência e Tecnologia de Alimentos, v.29, p.38-45, 2009. DOI: 10.1590/S0101-20612009000100007.

MARCHI, P.G.F. de; ROSSI JUNIOR, O.D.; CERESER, N.D.; SOUZA, V. de; REZENDE-LAGO, N.C.M. de; FARIA, A.A. de. Avaliação microbiológica e físico-química da carne bovina moída comercializada em supermercados e açougues de Jaboticabal - SP. Interdisciplinar: Revista Eletrônica da Univar, v.7, p.81-87, 2012.

MATHIAS, S.P.; ROSENTHAL, A.; GASPAR, A.; DELIZA, R.; SLONGO, A.P.; VICENTE, J.; MASSON, L.M.; BARBOSA, C. Alterações oxidativas (cor e lipídios) em presunto de peru tratado por alta pressão hidrostática (APH). Ciência e Tecnologia de Alimentos, v.30, p.852-857, 2010. DOI: 10.1590/ S0101-20612010000400003.

MEURER, F.; HAYASHI, C.; BOSCOLO, W.R. Digestibilidade aparente de alguns alimentos protéicos pela tilápia do Nilo (Oreochromis niloticus). Revista Brasileira de Zootecnia, v.32, p.1801-1809, 2003. DOI: 10.1590/S1516-35982003000800001.

OSAWA, C.C.; FELÍCIO, P.E. de; GONÇALVES, L.A.G. Teste de TBA aplicado a carnes e derivados: métodos tradicionais, modificados e alternativos. Química Nova, v.28, p.655-663, 2005. DOI: 10.1590/S0100-40422005000400019.

ÖZOGUL, F.; ÖZYURT, G.; ÖZOGUL, F.; KULEY, E.; POLAT, A. Freshness assessment of European eel (Anguilla anguilla) by sensory, chemical and microbiological methods. Food Chemistry, v.92, p.745-751, 2005. DOI: 10.1016/j.foodchem.2004.08.035.

SILVA, A.F.; GODOY, L.C.; FRANCO, M.L.R.S.; ASSIS, M.F., SOUZA, N.E.; VISENTAINER, J.V. Avaliação sensorial e composição proximal de camarões de água doce Macrobrachium rosembergii defumados. Ciência Animal Brasileira, v.11, p.770-774, 2010. DOI: 10.5216/cab.v11i4.4221. 
SOUZA, A.R.M. de; ARTHUR, V.; CANNIATTI-BRAZACA, S.G. Efeito da radiação gama e do do armazenamento na oxidação lipídica e no colesterol de carne de cordeiros da raça Santa Inês. Ciência e Tecnologia de Alimentos, v.27, p.67-71, 2007. DOI: 10.1590/S0101-20612007000100012.

SOUZA, M.L.R. de; BACCARIN, A.E.; VIEGAS, E.M.M.; KRONKA, S. do N. Defumação da tilápia do Nilo (Oreochromis niloticus) inteira eviscerada e filé: aspectos referentes às características organolépticas, composição centesimal e perdas ocorridas no processamento. Revista Brasileira de Zootecnia, v.33, p.27-36, 2004. DOI: 10.1590/S1516-35982004000100005.

SOUZA, M.L.R. de; VIEGAS, E.M.M.; SOBRAL, P.J. do A.; KRONKA, S. do N. Efeito do peso da tilápia do Nilo (Oreochromis niloticus) sobre o rendimento e a qualidade de seus filés defumados, com e sem pele. Ciência e Tecnologia de Alimentos, v.25, p.51-59, 2005. DOI: 10.1590/S0101-20612005000100009.

TORRES, E.A.F.S.; MACHADO, F.M.S. Alimentos em questão: uma abordagem técnica para as dúvidas mais comuns. São Paulo: Ponto Crítico, 2001. 160p.

VANDERZANT, C.; SPLITTSTOESSER, D.F. (Ed.). Compendium of methods for the microbiological examination of foods. Washington: APHA, 1992. 1250p.

VYNCKE, W. Direct determination of the thiobarbituric acid value in trichloracetic acid extracts of fish as a measure of oxidative rancidity. Fette, Seifen, Anstrichmittel, v.72, p.1084-1087, 1970. DOI: 10.1002/lipi.19700721218.

$\overline{\text { Recebido em } 25 \text { de julho de } 2011 \text { e aprovado em } 24 \text { de junho de } 2013}$ 